\title{
Predictors of Performance of the Maritime Academy of Asia and the Pacific (MAAP) in the OIC Navigational Watch Licensure Examination
}

\author{
Jose Manabat Barlis Jr. and Josefin Datu Fajardo III \\ Math and Sciences Courses, Maritime Academy of Asia and the Pacific, Philippines
}

\begin{abstract}
The study aimed to assess the predictors of performance administered by the Philippine Regulation Commission (PRC) in the licensure examination of Maritime Academy of Asia and the Pacific (MAAP) for Academic Year 2007-2011. Specifically, this also aimed to answer the following questions: demographic profile of the maritime graduates, the college related factors, administrative related factors, the level of scholastic achievement of the graduates, and the performance of the graduates in the licensure examination. A total of one hundred seventy three (173) graduates of MAAP from Class 2007-2011 were utilized as the respondents for the study. The study found out that the results of pre board examination and scholastic achievement of the graduates had significant effect on the performance of the graduates in O.I.C Navigational Watch Licensure Examination. Other variables found out to have no significant effect on the result of the licensure examination of the graduates. Therefore, the null hypotheses that the demographic profile of the graduates, college related factors, and administrative related factors has no significant effect on scholastic the achievement of the students were accepted. However, the null hypothesis that scholastic achievement of the students has no significant effect on the performance in maritime licensure examination was rejected. The same way, the null hypothesis that the demographic profile of the graduates, college related factors and the administrative related factors has no significant effect on the performance in Officer in Charge-Navigational Watch licensure Examination were accepted.
\end{abstract}

Keyword: Regimental Training, Licensure Examination, Maritime Academy of Asia and the Pacific, Scholastic Achievement, Philippine Regulation Commission (PRC), Administrative Related Factors, College related factors

\section{Introduction}

The competitiveness of seafarers in the Philippines is measured not only in terms of their performance in the school where they graduated, but also in the results of their licensure examinations, which was administered by the Professional Regulations Commission (PRC). Every graduate of maritime courses must possess PRC license for them qualify and fit for the position as deck officers and marine engineers. It follows that the performance in Licensure Examinations is definitely a major key point indicator of their readiness for shipboard employment in a globally competitive maritime industry.

Corresponding author: Jose Manabat Barlis Jr, EdD, assistant profesor III, research field: physics and curriculum development. E-mail: jun_barlis@yahoo.com.ph.
Having realized the demand by the global maritime sector in producing competent and qualified deck officers and marine engineers, several maritime institutions in the Philippines were built not only to develop students excellence in the field of academics but also the leadership traits that every individual must possess. MAAP as one of the leading maritime institutions in the Philippines enhances the capability of students through continuing program of development for excellence, competent and well trained faculty members, up to date instructional system/ materials, state of the art laboratories, sophisticated simulators, student personnel services, support from the administrators and sufficient on-the-job training on board ship. Aside from the rigorous academic instructions, MAAP also incorporated regimental training in developing the 
student's leadership traits, camaraderie among members, seniority and a structured lifestyle. Thus promotes personal development and management skills while studying.

However, no matter how the top management of every institution developed and elevates the level of education, it is undeniably true that some of the graduates cannot pass the licensure examination on the first take of examination especially for the Officer in Charge (OIC) of Navigational Watch. Further, among their graduates, small percentage passed the PRC licensure examination against the national passing rate.

Likewise, based on the data of Philippine Regulation Commission, the national passing rate for the Marine Deck Officers-OIC-Navigational Watch is quite low compared to other maritime course like Marine Engineering Officers-OIC-Engineering Watch Licensure Examination. The average national passing rate of Marine Deck Officers-OIC-Navigational Watch Licensure Examination from 2007-2011 is $48.17 \%$ while the average national passing rate of the Marine Engineering Officers-OIC-Engineering Watch Licensure Examination of the same year is $52.43 \%$. Likewise, MAAP also has low percentage of passing rate on the OIC Navigational Watch licensure examination compared to Marine Engineering Licensure Examination.

Therefore, it is deemed necessary to find out the predictors of performance in OIC-Navigational Watch Licensure Examination given by the PRC to the graduates of MAAP taking Bachelor of Science in Marine Transportation (BSMT) so that necessary actions may be considered in modifying educational approach and other extracurricular activities to their students that will ensure producing high quality of graduates and maintain competitive Filipino deck officers and marine engineers in the world of maritime profession.

\subsection{Conceptual Framework}

This study identified the profile of the respondents, college related factors and administrative related factors as the independent variables. The dependent/ independent variable considered is the scholastic achievement (GPA) of the students. The performance of the graduates in Maritime Licensure Examination is the dependent variable.

The predictors on Maritime Licensure Examination on the performance were measured using the results on the demographic profile of the graduates such pre board examination result and if the respondent attended review classes or not. The college related factors such as regimental and curriculum relevance as mandated by the Commission on Higher Education (CHED) and as required by the institution were utilized to determine if it affects the performance of graduates in their scholastic achievement and to their maritime profession. Likewise, scholastic achievement or the Grade Point Average (GPA) was also considered in the study. It is used to determine if it affects the performance of the students who graduated from maritime institution to their licensure examination.

The researcher employed the tracer's survey to the graduates of MAAP and used social networking sites such as Facebook, Twitter, and Yahoo mail in conducting the study. In the survey, it includes regimental training incorporated to their academic curriculum to determine if the regimental related factors affect on the performance of the graduates as well as the administrative related factors in terms of disciplinary actions, merit and administrative system and their scholastic achievement. Since the respondents were the graduates, the researcher used convenient sampling to determine the number of respondents for the study. The study was limited during the Academic Year 2007-2011. Data gathering procedures and testing were made in order to find sufficient information that supported this study.

Data obtained from the results of the interviews, and questionnaires were analyzed and interpreted using the prescribed statistical treatment. 


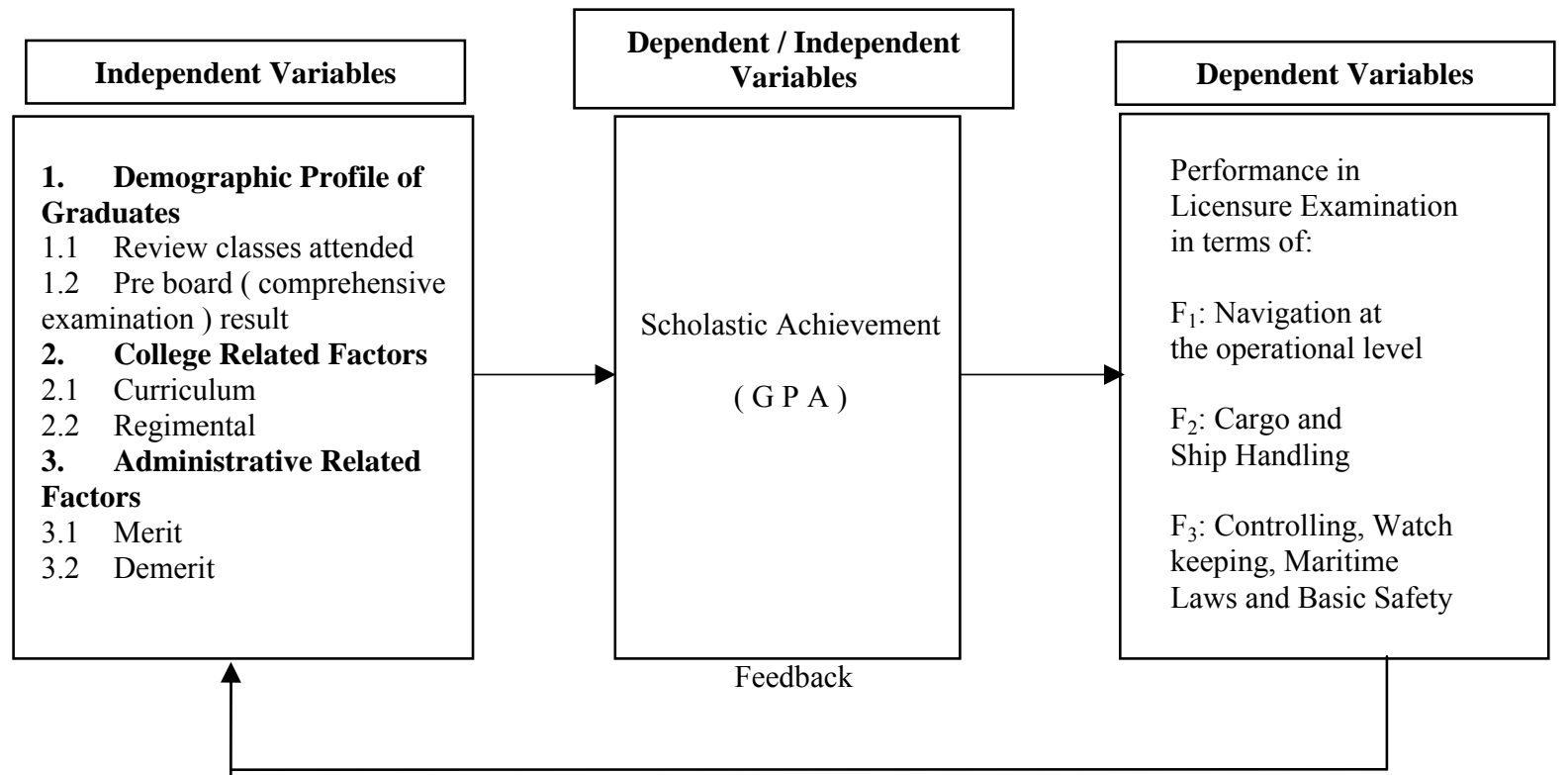

Fig. 1 The paradigm of the study.

\subsection{Hypotheses}

The following hypotheses were tested: (1) The demographic profile of the graduates, college related factors, and administrative related factors has no significant effect on scholastic the achievement of the students; (2) The scholastic achievement of the students has no significant effect on the performance in maritime licensure examination; and (3) The demographic profile of the graduates, college related factors and the administrative related factors has no significant effect on the performance in OIC Navigational Watch licensure Examination.

\section{Methods and Techniques of the Study}

Descriptive method and regression modeling were used as methods of analysis for this study. On the present study, since the purpose is to determine the predictors of performance on Maritime Licensure Examination, the researcher used the regression modeling instead of the correlation. Regression modeling was used to provide quantitative perspective where data is used to support the arguments formulated from the descriptive method.

It is said that in regression, independent variables, which at present study are the demographic profile of the graduates, college related factors, and administrative related factors, and the dependent variable, is the scholastic achievement of the students or the Grade Point Average (GPA) with respect to the independent variables. The performance of the graduates in maritime licensure examination will be considered as the dependent variable with respect to the scholastic achievement of the students. Regression is also the commonly used statistical technique when the purpose of the analysis is to identify the determinants or set of factors affecting a particular variable of interest. The main purpose in using the regression is that, the contribution of each factor on the overall effect/s of all factors on the dependent variable is estimated with respect to other factors within the model. Regression is important since one of the factors may be significantly related with the dependent variable when it is the only variable tested as a factor, but would be later become insignificant when other more important factors were introduced into the model. In the present study, logistic regression can be used to predict a dependent variable on the basis of continuous and/or categorical independents and to determine the effect size of the independent variables on the dependent; to rank the 
relative importance of independents; to assess interaction effects; and to understand the impact of covariate control variables.

\subsection{Population of the Study}

Convenient sampling method was used to determine the respondents of the study. The researcher sent survey questionnaire to the graduates of MAAP from class 2007-2011 using social networking sites. However, only those graduates who had internet access and contact information from the registrar's office were given survey questionnaire since the respondents of the study are the alumni of MAAP, the researchers have limited access to give the questionnaire personally to the respondents.

\subsection{Statistical Treatment of Data}

The data gathered using the questionnaires as well as the secondary data were coded, tabulated, and treated using various descriptive statistics like weighted mean, frequency counts, and percentage as well as inferential statistics such as $t$-test, Mann-Whitney U-test, and correlation analysis. The data generated were statistically analyzed with the aid of the statistical software called SPSS. The levels of significance for all statistical tests were set at 0.05 level. SPSS provides the exact significance level of each statistical test for comparison with 0.05 level by the researcher.

Various statistical tools were employed such as: Frequency and percentage counts were used to describe the demographic profile of the maritime graduates in terms of review classes attended and pre board examination result. Mean and corresponding descriptive rating were used to present the college related factors, and administrative related factors. Moreover, frequency, percentage, mean and standard deviation were utilized to explain the level of scholastic achievement and PRC licensure examination performance of the graduates.

Further, various inferential statistics were employed to treat the relationship of the student's profile, college and administrative related factors and the level of scholastic achievement and performance of graduates in the licensure examination. Independent Sample $t$-test was used to determine the significant difference on level of scholastic achievement and PRC performance between the categories of the profile variables. To ensure reliability of the findings, Mann-Whitney U-test, the nonparametric version of $t$-test, was used. Mann-Whitney U-test involves analysis of mean ranks to determine if significant differences in categories. On the other hand, correlation analyses were used to determine significant relationships among college and administrative related factors and the level of scholastic achievement and performance of graduates in the licensure examination. Pearson correlation (r), which measures the degree to which two quantitative variables are related, ranges from -1 to +1 , wherein -1 implies perfect inverse or negative relationship, +1 indicates perfect direct or positive relationship and zero signifies absence of linear association but not total absence of relationship. For easier interpretation of correlation coefficients, the following is adopted.

Moreover, correlation was also used to explain how the scholastic achievement of the graduates affects the performance in licensure examination. Coefficient of

Table 1 Distribution of students in terms of the number of graduates per class and the percentage of respondents.

\begin{tabular}{llll}
\hline Class & Number of graduates & Number of respondents & Percentage of the respondents to the graduates \\
\hline 2011 & 54 & 40 & $74.07 \%$ \\
2010 & 53 & 29 & $54.72 \%$ \\
2009 & 64 & 31 & $48.44 \%$ \\
2008 & 53 & 35 & $66.04 \%$ \\
2007 & 67 & 38 & $56.72 \%$ \\
\hline Total & $\mathbf{2 9 1}$ & $\mathbf{1 7 3}$ & $\mathbf{5 9 . 4 5 \%}$ \\
\hline
\end{tabular}


correlation (R-squared), the square of the correlation coefficient was also used to better explain the relationships of variables. Coefficient of Determination measures the variance shared by two variables, that is, the proportion of dependent variable that is accounted for by the dependent variable according to Besag and Besag [1].

Furthermore, stepwise multiple linear regressions was used to determine which among the factors taken singly or in combination best predicts the performance of the graduates in the PRC licensure examination. Alicias [2] stated that stepwise regression analysis provides a convenient and algorithmic way of minimizing the error and/or magnitude of errors of this type by systematically weeding out the redundant (hopefully irrelevant) and statistically meaningless variables that got included in the equation as a result of a faulty conceptualization of the phenomenon under investigation, thereby leading to a faulty specification of the equation. Stepwise regression produces parsimonious or optimum equation or model that can more effectively predict and explain the dependent variable. This statistical procedure starts with a model with an independent variable and then includes variable that causes increase in the multiple $R^{2}$ as stated by Norusi [3]. Independent variables which are significantly correlated with the dependent variable are entered as predictors in building a regression model.

Multiple regression analysis procedure includes statistical tools such as multiple correlation $(R)$ and multiple coefficient of determination $\left(R^{2}\right), F$-test, $t$-test, standard error of estimate, and beta weights. ANOVA or $F$-test determines the significance of the regression equation while $t$-test measures the significance of each independent variable as predictor of the dependent variable. Standard error of the estimate is computed to measures the deviation of observations around the best fitting straight line. Beta coefficients or weights are standardized regression coefficients and are used to judge the relative importance of each of several independent variables (SPSS Training Department, 2000).

The statistical tests for this research are calculated using SPSS version 17. Hence, the actual levels of significance are readily available. The output levels of significance are then compared with 0.05 which is the set level of significance prior to this research.

To facilitate the study, the researcher decided to diverge from the complicated statistical techniques instead keep the procedure and the methodology simpler. Each score is given by the respondents to the considered variables was equally weighted and the average taken in each variable. After which, the result or the average are the one considered in the regression model.

\subsection{Summary of the Findings}

\subsubsection{Demographic Profile of the Students}

Review classes attended. Based on the data analysis, it shows that 156 or $90.17 \%$ of the respondents attended formal review before taking the licensure examination while only 17 or $9.82 \%$ of the respondents did not enroll in any review centers and choose to have their home review and used their stock knowledge during the licensure examination. It only means that the graduates of MAAP though they are provided with high standards of education, they still realized the importance of having a comprehensive review prior to taking the examination. It may also consider the assistance provided by the institution by allowing their graduates to have their review free of charge. MAAP shouldered all the expenses incurred during the review. One (1) month after graduation, MAAP compelled their graduates to return to MAAP for comprehensive review before taking the licensure examination.

Comprehensive examination results (pre-board Examination). Based on the data, it showed that 150 or $86.71 \%$ of the graduates passed the comprehensive examination given by the department of academics prior to their graduation. Only 23 or $13.29 \%$ failed on 
the first take of the examination.

The purpose of the comprehensive exam is to evaluate the student's mastery on the field(s) of study for all the subjects taken from first year to fourth year. MAAP in support of student's holistic development, they included comprehensive examination as part of their curriculum. Students need to pass the comprehensive examination for them to be able to complete all the requirements for graduation. They will undergo series of examination using the computer based assessment. Comprehensive examination comprises two (2) parts: Computer based assessment and Practical Assessment.

\subsection{On college Related Factors}

Curriculum relevance. the result of the findings implied that the graduates realized the importance of general education course content to the BSMT program to be relevant to PRC licensure examination and to their maritime profession except the Life and Works of Rizal, Sining ng Pakikipagtalastasan, and Pagbasa at Pagsulat sa Ibat-ibang Disiplina which have less relevance with regards to the licensure examination and to their maritime profession with a mean of 2.40, 2.16 and 2.14 respectively. Likewise, the perception of graduates to the curriculum relevance of professional subjects as required by CHED in parallel with their licensure examination revealed that the graduates agreed that all the subjects required and offered by the institution are highly relevant to their maritime profession. It demonstrated that seamanship 5-Ship Handling and Maneuvering with a mean of 4.90 and Navigation 1-4 topped the survey. They all believed that with these subjects, it improved their performance as maritime graduates. Also, One Year Seagoing Service or the On the Job Training (OJT) by the graduates claimed as the best teacher they ever had. OJT is one of the requirements of the STCW in which the students/ cadets will be engaged in the actual operation of the ship and the performance of their task which shall be documented in the CHED approved Training Record Book.

Regimental related factors. In terms of program content as perceived by the graduates as it affects their scholastic achievement, strongly agreed with a composite mean of 4.66 that regimental factor developed their character in their inner strength and linked them between values and behaviors. At the same time, it teaches them the conduct of behavior as required by conscience and obligations. The program content of regimental training demonstrates a student to be a good sample for subordinates in terms of appearance, bearing, performance of duty and personal conduct. It also developed the pride and esprit-de-corps as a product of good training. The same way, on the perception of graduates to the regimental related factors in terms of types of activities, with a composite mean of 4.68 , graduates strongly agreed that types of activities helped and prepared them as officers and leaders in the merchant marine profession. The types of activities also prepared them to be accountable at all time and stressed the need to develop healthy attitudes about the worth and importance of people, concepts or thing. It also prepares them to observe and follow strictly the classroom guidelines issued by the Dean of Academics. Non-observance of classroom procedures makes the student liable for appropriate disciplinary actions. Graduates strongly agreed that different types of activities behoove students to act in a professional manner, with propriety and decorum that characterize socially accepted behavior. While on the regimental related factors in terms of regimental routines and other related factors as perceived by the graduates it shows that the graduate's perception is very satisfactory with a composite mean of 4.38 , they agreed that regimental routines such as prescribed drills, conducts field day procedure, quarters inspection procedure and prohibition of hazing developed their physical aspect and sense of responsibility towards others. On the other hand, cancellation of liberty or leave wherein the authority 
may cancel the said privileges for just cause and when necessary for the benefit of the Academy got the lowest rating to the whole regimental related factors with a composite mean of 4.21 .

Overall rating of the regimental related factors as perceived by the graduates is excellent with a mean of 4.57 .

\section{Administrative Related Factors}

It illustrated that administrative related factors as perceived by the graduates found to be excellent with overall mean of 4.55. Respondents strongly agreed in terms of merit that leadership with 4.71 mean which demonstrates the ability of influencing others to perform well in the class, section, battalion, company or platoon activities by providing purpose, direction and motivation should be given rewards for outstanding conduct and behavior and recognizes exemplary feat or services rendered by the midshipman/woman within or outside the academy premises. Also, exemplary performances by the students must be recognized. As perceived by the graduates, academic achievement of the students that distinguish themselves through scholastic achievement manifested in their class standings and periodic assessments forms must be acknowledged for them to be motivated in striving for a higher grade and excellent performance.

Likewise, in terms of demerits, adherence to Regulation, Orders and Instruction with 4.69 mean such as disobedience of orders and regulations should be prioritized as perceived by the graduates in giving deficiency reports to eliminate reoccurrence of the same offense.

\section{Scholastic Achievement of the Graduates}

Function 1 or F1 include subjects such Ship Handling and Maneuvering, Terrestrial Navigation 1-2, Celestial Navigation 1-2, Deck Watch Keeping, Collision Regulations, Merchant Ships Search and Rescue, Electronic Navigation RADAR, Electronic
Navigation ARPA, Basic Marine Engineering and Meteorology and Oceanography. Function 2 or F2 includes Ship, Ship Routines and Construction, Cargo Handling and Stowage 1 and 2 and Stability and Trim and Function 3 or F3 includes Ship, Ship Routines and Construction, Stability and Trim, Basic Safety, Shipboard Personnel Management, Maritime Law and Marine Pollution and Prevention.

As the survey reveals, $49 \%$ of the respondents obtained good grades in Function 1 ranging from 84 to 87.99 while $34 \%$ with very good grades from 88 to 92.99. The average grade of respondents in Function 1 is 86.70 with standard deviation of 3.05 . This suggests that, on the average, the students have good performance with mean ranging from 83.65 to 89.75 .

Similarly, $45 \%$ of the respondents obtained good grades in Function 2 and 35\% got very good remarks while only $3.5 \%$ are excellent. The average grade of 86.98 with standard deviation of 3.71 implies that the graduates, on the average, have good academic performance in Function 2 such that the center of their grade distribution ranges from 83.27 to 90.99 .

For Function 3, 84\% have grades which are good to very good while $12 \%$ have satisfactory grade and three percent $(3 \%)$ are excellent. The average performance of the graduates in this subject is 87.60 with standard deviation of 2.86 .

Overall, majority or $97 \%$ of the respondents have grades ranging from good to very good GPA with only few who are satisfactory and excellent. The average GPA of the graduates is 88.38 and standard deviation of 2.22 .

The findings demonstrated that MAAP graduates strived harder in their studies while they were still in the academy. They still managed to focus on the academics in spite of demanding schedules. One factor that may consider is their study period every night from $1900 \mathrm{H}$ to $2200 \mathrm{H}$. During this period, students find time to ask for assistance/help of their colleagues in their difficulties, advance readings, preparation for the next topics, homework and at the 

in the OIC Navigational Watch Licensure Examination

same time they can focus to their lessons instead of watching television, playing computer and the like. Tutoring programs can become important learning strategies that will assist students in learning to solve problems, collaborate with others, and think creatively (Gordon 2005).

\section{Performance of the Graduates in the PRC Licensure Examination}

Table 4 presents the performance of the graduates in the PRC licensure examination. It should be noted that an examinee should get an average rate of at least $70 \%$ and with no grades below $60 \%$ in order to pass the $\mathrm{PRC}$ ratings.

It is observed from Table 4 that the highest mean ratings of the respondents is on Function 2 with mean of 76.94 and then on Function 1 with mean of 76.21. The average PRC Rating of 75.79 with standard deviation of 6.42 suggests that the center of distribution of data has a wide range which is from 69.37 to 82.21 .

Further, it can be gleaned from the table that $88 \%$ of the graduates passed F1, 84\% passed F2, $81 \%$ passed $\mathrm{F} 3$ and $86 \%$ passed the licensure examination.

It only means that the graduates realized the subjects under Function 1 are more interesting and easy to understand such as Navigation at the operational level. Used and full utilization of simulators and other laboratories developed the knowledge of the graduates during their stay in the academy.

6. Correlation of the student's profile, college and administrative related factors with the level of scholastic achievement and performance of graduates in the licensure examination

Table 5 presents the relationship of scholastic achievement and pre-board results of the graduates using $t$-test and Mann-Whitney $U$-test. Evidently, both $t$-test and Mann-Whitney U-test suggest that there are significant differences in the mean scholastic achievement of graduates when grouped according to whether they passed or failed in the pre-board examination.

Table 6 presents the relationship of scholastic achievement and attendance in review classes of the graduates using $t$-test and Mann-Whitney $U$-test.

The mean GPA (88.57) of those who passed the pre-board examination is significantly higher compared to that of those who failed this examination (87.27). This is evident with the $t$-value of 2.80 which

Table 4 PRC ratings of graduates.

\begin{tabular}{lllll}
\hline PRC Ratings & Mean & Std. Deviation & No. of Passers & \% of Passers \\
\hline F1 & 76.21 & 7.69 & 152 & 87.9 \\
F2 & 76.94 & 7.81 & 145 & 83.8 \\
F3 & 75.10 & 7.85 & 140 & 80.9 \\
Overall & 75.79 & 6.42 & 148 & 85.5 \\
\hline
\end{tabular}

Table 5 Pre-board and scholastic achievement of the graduates.

\begin{tabular}{llllllll}
\hline $\begin{array}{l}\text { Academic } \\
\text { achievement }\end{array}$ & Pre-board & Mean & Std. Deviation & $\begin{array}{l}\text { t-value } \\
\text { Sig. }\end{array}$ & $\begin{array}{l}\text { Mann-Whitney } U \text {-test } \\
\text { Sig. }\end{array}$ & Remarks \\
\hline F1 & Failed [n=26] & 84.90 & 2.47 & 3.35 & 1185.0 & Significant \\
& Passed [n=147] & 87.02 & 3.04 & 0.001 & 0.002 & Reject $\mathrm{H}_{0}$ \\
F2 & Failed & 85.42 & 2.69 & 2.35 & 1187.5 & Significant \\
& Passed & 87.26 & 3.81 & 0.020 & 0.002 & Reject $\mathrm{H}_{0}$ \\
F3 & Failed & 86.60 & 2.49 & 2.00 & 1421.5 & Significant \\
& Passed & 87.78 & 2.89 & 0.05 & 0.038 & Reject $\mathrm{H}_{0}$ \\
GPA & Failed & 87.27 & 2.06 & 2.80 & 1311.0 & Significant \\
& Passed & 88.57 & 2.20 & 0.006 & 0.011 & Reject $\mathrm{H}_{0}$ \\
\hline
\end{tabular}



in the OIC Navigational Watch Licensure Examination

Table 6 Attendance in review classes and scholastic achievement of the graduates.

\begin{tabular}{|c|c|c|c|c|c|c|}
\hline $\begin{array}{l}\text { Academic } \\
\text { achievement }\end{array}$ & $\begin{array}{l}\text { Attendance in } \\
\text { review classes }\end{array}$ & Mean & Std. Deviation & $\begin{array}{l}\mid t \text {-value } \\
\text { Sig. }\end{array}$ & $\begin{array}{l}\text { Mann-Whitney } U \text {-test } \\
\text { Sig. }\end{array}$ & Remarks \\
\hline \multirow{2}{*}{ F1 } & No $[n=17]$ & 86.42 & 3.89 & 0.398 & 1319.500 & Not Significant \\
\hline & Yes $[n=156]$ & 86.73 & 2.96 & 0.691 & 0.974 & Do Not Reject $\mathrm{H}_{0}$ \\
\hline \multirow{2}{*}{$\mathrm{F} 2$} & No & 86.58 & 3.09 & 0.473 & 1170.500 & Not Significant \\
\hline & Yes & 87.03 & 3.78 & 0.637 & 0.428 & Do Not Reject $\mathrm{H}_{0}$ \\
\hline \multirow{2}{*}{ F3 } & No & 87.59 & 2.67 & 0.026 & 1295.000 & Not Significant \\
\hline & Yes & 87.61 & 2.89 & 0.979 & 0.874 & Do Not Reject $\mathrm{H}_{0}$ \\
\hline \multirow{2}{*}{ GPA } & No & 88.48 & 2.52 & 0.195 & 1227.500 & Not Significant \\
\hline & Yes & 88.37 & 2.20 & 0.845 & 0.615 & Do Not Reject $\mathrm{H}_{0}$ \\
\hline
\end{tabular}

is significant at 0.01 and Mann-Whitney U-test value of 1311.0 which is significant at 0.011 . This result suggests that there is a significant relationship between the GPA and the pre-board examination such that, passers tend to have higher scores compared to those non-passers of the said examination.

As gleaned from Table 6, there are no significant differences in the performance of the graduates in F1, F2, F3 and GPA when grouped according to whether they attended review classes or not as evidenced by the values of $t$-test and Mann-Whitney U-test which are not significant at 0.05 level.

It is observed that the mean GPA of those who attended review classes, 88.37, is not significantly different from those who did not attend such classes, 88.37. The significance level $(0.195)$ of the $t$-value of 0.195 is greater than 0.05 level; hence, the value is not significant. Therefore, the null hypothesis is not rejected as the data is not sufficient to prove that there is no significant relationship between the two variables.

Table 7 presents the college related factors and the level of scholastic achievement of graduates considering the correlation coefficients of variables.

Noticeably, no significant relationships of variables are observed from the correlation coefficients reflected in Table 7. As shown, the overall college related factor obtained a negligible correlation coefficient of -0.038 with F1, 0.027 with F2, 0.051 with F3 and -0.002 with GPA. As perceived by the graduates, college related factors such as curriculum relevance, as required by CHED and by institution and regimental related factors has no significant effect to their scholastic achievement. Although MAAP included other courses to the existing curriculum of the BSMT, graduates perceived it as positive on their part. At the same time, regimental related factors does not affect the level of the performance of the graduates in terms of scholastic achievement. MAAP students were prepared to be physically and emotionally ready before they board their respective ships. Perceptions of the graduates differ from their perception while are still studying since they already understood the reasons of regimental in their life.

Table 8 presents the Administrative Related Factors and level of Scholastic Achievement of graduates considering the correlation coefficients of variables.

Noticeably, no significantly relationship exists between the perceptions of the students on the administrative related factors which include merit system and demerit system with their scholastic achievements. This is evident with the negligible correlation coefficients presented in Table 8 .

The results of the findings as perceived by the graduates show that it does not affect to their scholastic achievement since administrative related factors focused more on the leadership characteristics and traits of the individual. Merit and demerit systems give emphasize on the attitude and personality of the students and less on the academic side. It focuses on the development of oneself in terms of discipline, camaraderie, time management, accountability, and adherence to duty. 

in the OIC Navigational Watch Licensure Examination

Table 7 Correlation analysis of college related factors and level of scholastic achievement.

\begin{tabular}{|c|c|c|c|c|c|c|c|c|}
\hline \multirow{2}{*}{ College related factors } & \multicolumn{2}{|r|}{$\mathrm{F} 1$} & \multicolumn{2}{|r|}{$\mathrm{F} 2$} & \multicolumn{2}{|r|}{ F3 } & \multicolumn{2}{|r|}{ GPA } \\
\hline & r/ Sig. & Remarks & r/ Sig. & Remarks & r/ Sig. & Remarks & r/ Sig. & Remarks \\
\hline \multirow{2}{*}{ Program content } & -0.087 & negligible & -0.071 & negligible & -0.019 & negligible & -0.031 & negligible \\
\hline & 0.262 & Not significant & 0.361 & Not significant & 0.803 & Not significant & 0.693 & Not significant \\
\hline \multirow{2}{*}{ Types of activities } & -0.008 & negligible & 0.010 & negligible & -0.014 & negligible & 0.025 & negligible \\
\hline & 0.914 & Not significant & 0.894 & Not significant & 0.857 & Not significant & 0.745 & Not significant \\
\hline \multirow{2}{*}{ Regimental routines } & -0.053 & negligible & -0.030 & negligible & -0.011 & negligible & -0.007 & negligible \\
\hline & 0.493 & Not significant & 0.701 & Not significant & 0.885 & Not significant & 0.925 & Not significant \\
\hline \multirow{2}{*}{ Regimental } & -0.060 & negligible & -0.036 & negligible & -0.018 & negligible & -0.005 & negligible \\
\hline & 0.437 & Not significant & 0.640 & Not significant & 0.816 & Not significant & 0.950 & Not significant \\
\hline \multirow{2}{*}{$\begin{array}{l}\text { Relevance as required } \\
\text { by CHED }\end{array}$} & 0.070 & negligible & 0.114 & negligible & $0.20^{*}$ & Low & 0.028 & negligible \\
\hline & 0.357 & Not significant & 0.136 & Not significant & 0.010 & Significant & 0.719 & Not significant \\
\hline \multirow{2}{*}{$\begin{array}{l}\text { Relevance as required } \\
\text { by institution }\end{array}$} & -0.115 & negligible & -0.024 & negligible & 0.016 & negligible & -0.073 & negligible \\
\hline & 0.131 & Not significant & 0.749 & Not significant & 0.831 & Not significant & 0.341 & Not significant \\
\hline \multirow{2}{*}{$\begin{array}{l}\text { Relevance of } \\
\text { professional subjects }\end{array}$} & 0.042 & negligible & 0.044 & negligible & 0.014 & negligible & 0.076 & negligible \\
\hline & 0.586 & Not significant & 0.567 & Not significant & 0.858 & Not significant & 0.318 & Not significant \\
\hline \multirow{2}{*}{ Overall relevance } & 0.000 & negligible & 0.062 & negligible & 0.110 & negligible & 0.010 & negligible \\
\hline & 0.999 & Not significant & 0.416 & Not significant & 0.150 & Not significant & 0.900 & Not significant \\
\hline \multirow{2}{*}{$\begin{array}{l}\text { Overall college related } \\
\text { factor }\end{array}$} & -0.038 & negligible & 0.027 & negligible & 0.051 & negligible & -0.002 & negligible \\
\hline & 0.623 & Not significant & 0.728 & Not significant & 0.512 & Not significant & 0.981 & Not significant \\
\hline
\end{tabular}

**-significant at 0.01 level, *-significant at 0.05 level, ns-not significant. Legend: $\pm 0.80- \pm 1.0$ high correlation. $\pm 0.60- \pm 0.79$ moderately high correlation. \pm 0.40 - \pm 0.59 moderate correlation. \pm 0.20 - \pm 0.39 low correlation. $\pm 0.01- \pm 0.19$ negligible correlation.

Table 8 Correlation analysis of administrative related factors and level of scholastic achievement.

\begin{tabular}{lllllllll}
\hline \begin{tabular}{l} 
College and $\begin{array}{l}\text { administrative related } \\
\text { factors }\end{array}$ \\
\cline { 2 - 8 } Merit system
\end{tabular} & r/ Sig. & Remarks & r/ Sig. & Remarks & r/ Sig. & Remarks & r/ Sig. & Remarks \\
& 0.090 & negligible & 0.100 & negligible & 0.104 & negligible & -0.020 & negligible \\
Demerit system & 0.246 & Not significant & 0.195 & Not significant & 0.177 & Not significant & 0.800 & Not significant \\
& -0.079 & negligible & -0.083 & negligible & -0.058 & negligible & -0.017 & negligible \\
Administrative & 0.309 & Not significant & 0.286 & Not significant & 0.457 & Not significant 0.823 & Not significant \\
& -0.076 & negligible & -0.048 & negligible & 0.011 & negligible & -0.036 & negligible \\
& 0.324 & Not significant & 0.534 & Not significant & 0.889 & Not significant 0.643 & Not significant \\
\hline
\end{tabular}

Table 9 presents the relationship of pre-board and the performance of graduates in the PRC licensure examination using $t$-test and Mann-Whitney $U$-test.

Direct inspection of the PRC ratings suggests that the performance of the graduates who passed the pre-board exam is better than those who failed in this exam.

The Average PRC Rating of 77.56 by the graduates who passed the pre-board exam, 77.56 is significantly higher compared to those who failed with Average of 65.18. The t-test value of 11.38 is significant at 0.01 ; hence, there is a significant difference between the performance of two groups and the null hypothesis is rejected. Thus, there is a significant relationship between pre-board examination and PRC licensure performance.

Table 10 presents the relationship of scholastic achievement and the attendance in review classes of the graduates using $t$-test and Mann-Whitney $U$-test.

Direct inspection of the mean performance of the graduates in the PRC licensure examination showed that there are no significant differences between those who attended review classes and those who did not. This is confirmed by the results of t-test and Mann-Whitney $U$-test wherein the statistical values are 
Table 9 Pre-board and performance of graduates in the licensure examination.

\begin{tabular}{|c|c|c|c|c|c|c|}
\hline $\mathrm{PRC}$ ratings & Pre-board & Mean & Std. Deviation & $\begin{array}{l}\mid t \text {-value } \\
\text { Sig. }\end{array}$ & $\begin{array}{l}\text { Mann-Whitney } U \text {-test } \\
\text { Sig. }\end{array}$ & Remarks \\
\hline \multirow{2}{*}{ F1 } & Failed $[n=26]$ & 64.12 & 8.34 & 11.61 & 216.5 & Significant \\
\hline & Passed [n=147] & 78.35 & 5.20 & 0.000 & 0.000 & Reject $\mathrm{H}_{0}$ \\
\hline \multirow{2}{*}{$\mathrm{F} 2$} & Failed & 66.58 & 8.03 & 8.83 & 438.5 & Significant \\
\hline & Passed & 78.78 & 6.20 & 0.000 & 0.000 & Reject $\mathrm{H}_{0}$ \\
\hline \multirow{2}{*}{ F3 } & Failed & 67.38 & 7.40 & 5.96 & 678.0 & Significant \\
\hline & Passed & 76.46 & 7.12 & 0.000 & 0.000 & Reject $\mathrm{H}_{0}$ \\
\hline \multirow{2}{*}{ Average } & Failed & 65.79 & 6.18 & 11.38 & 192.5 & Significant \\
\hline & Passed & 77.56 & 4.59 & 0.000 & 0.000 & Reject $\mathrm{H}_{0}$ \\
\hline
\end{tabular}

Table 10 Attendance in review classes and performance of graduates in the licensure examination.

\begin{tabular}{|c|c|c|c|c|c|c|}
\hline $\mathrm{PRC}$ ratings & $\begin{array}{l}\text { Attendance in } \\
\text { review classes }\end{array}$ & Mean & Std. Deviation & $\begin{array}{l}\mid t \text {-value } \\
\text { Sig. }\end{array}$ & $\begin{array}{l}\text { Mann-Whitney } U \text {-test } \\
\text { Sig. }\end{array}$ & Remarks \\
\hline \multirow{2}{*}{ F1 } & No $[n=17]$ & 75.59 & 9.07 & 0.353 & 1285.0 & Not Significant \\
\hline & Yes $[n=156]$ & 76.28 & 7.55 & 0.301 & 0.834 & Accept $\mathrm{H}_{0}$ \\
\hline \multirow{2}{*}{$\mathrm{F} 2$} & No & 75.82 & 8.51 & 0.592 & 1214.500 & Not Significant \\
\hline & Yes & 77.06 & 7.75 & 0.621 & 0.569 & Accept $\mathrm{H}_{0}$ \\
\hline \multirow{2}{*}{ F3 } & No & 74.59 & 9.04 & 0.561 & 1225.000 & Not Significant \\
\hline & Yes & 75.15 & 7.74 & 0.281 & 0.606 & Accept $\mathrm{H}_{0}$ \\
\hline \multirow{2}{*}{ Average } & No & 75.19 & 7.41 & 0.449 & 1270.000 & Not Significant \\
\hline & Yes & 75.86 & 6.33 & 0.407 & 0.775 & Accept $\mathrm{H}_{0}$ \\
\hline
\end{tabular}

not significant at 0.05 level. Therefore, the null hypotheses are rejected. It confirmed that graduates of MAAP are still willing to refresh their knowledge of what the have learned while are still studying. They are not complaisant on the possibility that they may fail in the licensure examination. MAAP manages to support the review expenses of the graduates for them to have a quality review materials and review center itself in support of producing world class seafarer and to become officers of their respective ships.

Table 11 presents the college related factors and the performance of graduates in the PRC licensure examination considering the correlation coefficients of variables.

It can be gleaned from Table 11 that program content, regimental routines and overall regimentation are significantly correlated with $\mathrm{F} 1$; however to a low and inverse extent. Hence, the relationships are not that sizeable to be of meaningful value to the research. Also, relevance as required by institution and overall college related factors are significantly correlated with F1, but to a low and negative extent.
Table 12 presents the administrative related factors and the performance in the PRC licensure examination considering the correlation coefficients of variables.

Negligible correlations are evidently shown in Table 12, suggesting no significant relationship between Administrative Related Factors and performance in the PRC Licensure Examination. It is strongly statement that the regimental factors such as program content, types of activities, and regimental routines do not affect the performance of the graduates in the licensure examination as perceived by the graduates. It only means that as the person grows older their perception on life changes. Palgi and Shmotkin [5] stated that life satisfaction grows as people become older because they become wiser and more knowledgeable, so they begin to see that life will be better as they grow older and understand the important things in life more

\section{Achievement of the Graduates and Performance in Licensure Examination}

Table 13 presents the relationship of scholastic 

in the OIC Navigational Watch Licensure Examination

Table 11 Correlation analysis of college related factors and prc performance.

\begin{tabular}{lllllllll}
\hline \multirow{2}{*}{ college related factors } & \multicolumn{2}{c}{ F1 } & \multicolumn{2}{c}{ F2 } & F3 & Average rating \\
\cline { 2 - 8 } Program content & $-0.153^{*}$ & Low & -0.088 & negligible & -0.041 & negligible & -0.121 & Negligible \\
& 0.047 & Significant & 0.255 & Not significant & 0.594 & Not significant 0.118 & Not significant \\
Types of activities & -0.120 & negligible & -0.061 & negligible & 0.004 & negligible & -0.086 & Negligible \\
& 0.121 & Not significant & 0.430 & Not significant & 0.957 & Not significant 0.268 & Not significant \\
Regimental routines & $-0.172^{*}$ & Low & -0.079 & negligible & 0.036 & negligible & -0.093 & negligible \\
& 0.026 & Significant & 0.309 & Not significant & 0.641 & Not significant 0.229 & Not significant \\
Regimental & $-0.183^{*}$ & Low & -0.093 & negligible & 0.001 & negligible & -0.122 & negligible \\
& 0.017 & Significant & 0.228 & Not significant & 0.988 & Not significant 0.114 & Not significant \\
Relevance as required & 0.032 & negligible & -0.060 & negligible & -0.027 & negligible & 0.008 & negligible \\
by CHED & 0.679 & Not significant & 0.442 & Not significant & 0.728 & Not significant 0.914 & Not significant \\
Relevance as required & $-0.169^{*}$ & Low & -0.113 & negligible & -0.119 & negligible & -0.139 & negligible \\
by institution & 0.028 & Significant & 0.145 & Not significant & 0.122 & Not significant 0.071 & Not significant \\
Relevance of & -0.103 & negligible & 0.044 & negligible & 0.030 & negligible & -0.006 & negligible \\
professional subjects & 0.182 & Not significant & 0.568 & Not significant & 0.702 & Not significant 0.942 & Not significant \\
Overall relevance & -0.095 & negligible & -0.063 & negligible & -0.055 & negligible & -0.058 & negligible \\
& 0.220 & Not significant & 0.417 & Not significant & 0.481 & Not significant 0.451 & Not significant \\
Overall college related & $-0.175^{*}$ & Low & -0.098 & negligible & -0.030 & negligible & -0.114 & negligible \\
factor & 0.023 & Significant & 0.207 & Not significant & 0.697 & Not significant 0.139 & Not significant \\
\hline
\end{tabular}

**_-significant at 0.01 level, *_-significant at 0.05 level, ns — not significant.

Table 12 Correlation Analysis of Administrative Related Factors and Performance in the PRC Licensure Examination.

\begin{tabular}{lllllllll}
\hline Administrative & \multicolumn{3}{c}{ F1 } & \multicolumn{2}{c}{ F2 } & \multicolumn{2}{c}{ F3 } & \multicolumn{2}{c}{ Average Rating } \\
\cline { 2 - 9 } related factors & r/ Sig. & Remarks & r/ Sig. & Remarks & r/ Sig. & Remarks & r/ Sig. & Remarks \\
\hline \multirow{2}{*}{ Merit System } & -0.085 & negligible & -0.058 & negligible & 0.055 & negligible & -0.032 & negligible \\
& 0.269 & Not significant & 0.454 & Not significant & 0.478 & Not significant 0.676 & Not significant \\
Demerit System & -0.092 & negligible & -0.008 & negligible & -0.076 & negligible & -0.057 & negligible \\
& 0.236 & Not significant & 0.917 & Not significant & 0.326 & Not significant 0.462 & Not significant \\
Administrative & -0.106 & negligible & -0.040 & negligible & -0.011 & negligible & -0.053 & negligible \\
& 0.171 & Not significant & 0.605 & Not significant & 0.888 & Not significant 0.493 & Not significant \\
\hline
\end{tabular}

Table 13 Correlation $(r)$ and coefficient of determination $\left(r^{2}\right)$ of scholastic achievement and performance of graduates in the licensure examination.

\begin{tabular}{|c|c|c|c|c|c|c|c|c|c|c|c|c|}
\hline \multirow{3}{*}{$\begin{array}{l}\text { Scholastic } \\
\text { achievement }\end{array}$} & \multicolumn{12}{|c|}{ PRC licensure examination rating } \\
\hline & \multicolumn{3}{|c|}{$\mathrm{F} 1$} & \multicolumn{3}{|c|}{$\mathrm{F} 2$} & \multicolumn{3}{|c|}{ F3 } & \multicolumn{3}{|c|}{ Average Rating } \\
\hline & $\mathrm{R}$ & $r^{2}$ & remarks & $\mathrm{r}$ & $r^{2}$ & remarks & $\mathrm{r}$ & $\mathrm{r}^{2}$ & remarks & $\mathrm{r}$ & $r^{2}$ & remarks \\
\hline Academic F1 & $0.44^{* *}$ & 0.19 & moderate & $0.47^{* *}$ & 0.22 & moderate & $0.48^{* *}$ & 0.23 & moderate & $0.55^{* *}$ & 0.30 & moderate \\
\hline Academic F2 & $0.45^{* *}$ & 0.20 & moderate & $0.33^{* *}$ & 0.11 & low & $0.30^{* *}$ & 0.09 & low & $0.46^{* *}$ & 0.21 & low \\
\hline Academic F3 & $0.42^{* *}$ & 0.18 & moderate & $0.24^{* *}$ & 0.06 & low & $0.13^{\mathrm{ns}}$ & 0.02 & negligible & $0.35^{* *}$ & 0.12 & low \\
\hline GPA & $0.45^{* *}$ & 0.20 & moderate & $0.51^{* *}$ & 0.26 & moderate & $0.42^{* *}$ & 0.18 & moderate & $0.56^{* *}$ & 0.31 & moderate \\
\hline
\end{tabular}

**-significant at 0.01 level, *-significant at 0.05 level, ns-not significant. Legend: $\pm 0.80- \pm 1.0$ high correlation. $\pm 0.60- \pm 0.79$ moderately high correlation. $\pm 0.40- \pm 0.59$ moderate correlation. $\pm 0.20- \pm 0.39$ low correlation. $\pm 0.01- \pm 0.19$ negligible correlation.

achievement and performance of graduates in the PRC licensure examination using correlation coefficients $(r)$ and coefficient of determination $\left(r^{2}\right)$.

As shown in Table 13, the scholastic achievements of the graduates are significantly correlated to their performance in the licensure examination.

Academic F1 is significantly correlated with the PRC F1 having a moderate correlation of 0.44 and a 
coefficient of determination of 0.19 . This suggests that $19 \%$ of the variability in the ratings of the graduates in F1 can be attributed to their performance in their academic F1, while the other $81 \%$ can be due to other factors. It is unlikely that Academic F1 correlates with F2 and F3 having correlation coefficients of 0.47 and 0.48 , respectively, more than with its corresponding F1 in the PRC examination. However, this should not be a surprise as Academic F1 is strongly correlated with Academic F2 with correlation coefficient of 0.84 and with Academic F3 with 0.64. These mean that the academic performances of the respondents are inter correlated. Overall, the academic performance of the graduates correlates moderately with the average PRC rating with a coefficient of 0.55 . The coefficient of determination, 0.30 suggests that $30 \%$ of the variability in the PRC rating can be attributed to the variability in the performance of the graduates in Academic F1.

Further, Academic F2 significantly correlates with the PRC F2, however to a low extent such that only $11 \%$ of the variability in the performance of graduates in the PRC F2 can be explained by the Academic F2. PRC F2 also correlates moderately with Academic F2 with a correlation coefficient of 0.45 and also correlates to a low extent with Academic F3 having a correlation coefficient of 0.30 .

With regards to PRC F3, it does not significantly correlates with its corresponding Academic F3 having a negligible correlation of .13. However, PRC F3 is moderately correlated with Academic F3 $(r=0.42)$.

On the other hand, GPA, which covers all academic subjects of students, significantly correlates with the three functions of PRC examination having correlation coefficients of 0.45 wit $\mathrm{F} 1,0.51$ with $\mathrm{F} 2$ and 0.42 with F3. GPA correlates moderately with PRC average rating having a correlation coefficient of 0.56 and coefficient of determination of 0.31 . Hence, $31 \%$ of the variability in the performance of the graduates in the PRC licensure examination can be explained by the variation in their GPA while the other $69 \%$ can be due to other factors.

\section{Significant predictors of success in maritime licensure Examination}

This part summarizes the significant predictors of success in maritime licensure examination.

Table 14 presents the regression models with significant predictors of PRC Average Rating using stepwise selection. The statistics computed include multiple correlation coefficient $(R)$, adjusted coefficient of multiple regression $\left(R^{2}\right), F$ values, and standard error of estimate, beta weights and $t$-values. The $F$ statistic measures the significance of the whole model while each predictor whether each is significant to be part of the equation or not. The standard error of the estimate is a standard deviation type summary of the dependent variable that measures the deviation of observations around the best fitting straight line. Beta coefficients are standardized regression coefficients and are used to judge the relative importance of each of several independent variables (SPSS Training Department, 2000).

In Table 14, the three (3) models are output of stepwise regression procedure with PRC Average Rating as the regressor and the significant student profile and scholastic achievements as the predictor variables. Only three (3) predictor variables are retained

Table 14 Stepwise regression analysis output with PRC Average Rating as the regressor.

\begin{tabular}{llllllll}
\hline Model & Predictors & $R$ & Adjusted $R^{2}$ & $F$ Value & Standard Error of Estimate & Beta weights & $T$ values \\
\hline 1 & Pre-board & 0.61 & 0.37 & $100.310^{* *}$ & 4.61 & 0.61 & $10.015^{* *}$ \\
2 & Pre-board + & \multirow{2}{*}{0.75} & 0.56 & $109.331^{* *}$ & 3.84 & 0.52 & $9.92^{* *}$ \\
& GPA & & & & 0.45 & $8.62^{* *}$ \\
& Pre-board + & \multirow{2}{*}{0.76} & 0.58 & $76.978^{* *}$ & \multirow{2}{*}{3.78} & 0.49 & $9.32^{* *}$ \\
3 & GPA + & & & & 0.34 & $4.90^{* *}$ \\
& Academic F1 & & & & & 0.17 & $2.42^{* *}$ \\
\hline
\end{tabular}

**_-Significant at 0.01 level; *_-Significant at 0.05 level. 
during the process of stepwise selection due to multicolinearity with the other variables. Further, in the regression models, it can be surmised that the regression models are significant as manifested by the F-values which are significant at 0.01 level. Each predictor variables are also significant in predicting the dependent variable as implied by the $t$-values which are significant at 0.01 level; though 0.05 is the accepted level of significant in this study.

Model 1 revealed that pre-board performance is the first predictor selected having the highest correlation coefficient of 0.613 and adjusted coefficient of determination of 0.37 which indicate that $37 \%$ of the variability in the PRC Average Rating can be explained by the variability in the performance of the graduates in the pre-board exam while the other $63 \%$ can be due to other factors. The $F$ value of 100.31 significant at 0.01 level indicates that the first model is significant while the $t$-value of 10.015 significant at 0.01 level signifies that pre-board rating is a significant predictor of PRC Average Rating. The beta coefficient or weight is similar to the correlation coefficient.

In Model 2, GPA is added as a predictor of PRC Average Rating. The adjusted $R^{2}$ value of .56 indicates that pre-board rating and Academic F1 collectively attributes $56 \%$ of the variance in the PRC Average Rating while the other $44 \%$ can be due to other factors. With this, it can be noted that $19 \%$ variance, which is a sizeable value, was added with the inclusion of GPA in the model. The standard beta weights suggest that Pre-board is relatively more important predictor of PRC Average Rating compared to GPA.

In Model 3, Academic GPA was added as predictor of PRC Average Rating. Hence, the adjusted $\mathrm{R}$-squared is raised to 0.58 suggesting that $58 \%$ of the variability in the PRC Average Rating can be explained by the variability in the pre-board, GPA and Academic GPA as a whole while the other $42 \%$ can be attributed by other factors. Evidently, only $2 \%$ variance was added in the Model with the addition of
Academic GPA in the model. Further, considering the beta weights, it can be surmised that Pre-board is the best predictor of PRC Average rating and followed by GPA and Academic F1. Also, the best model is the third model as it has the highest coefficient of determination and lowest standard error of estimate.

\section{Recommendation}

Based on the conclusions drawn from this study, the following recommendations were drawn:

MAAP should have a strict policy on the scholastic achievement of the students. They may improve academic policies such as exemption policy and maintained high grades for all students since they are all scholars and to meet the requirements of the sponsoring companies.

It is recommended to input additional questions to the data bank for the computer based assessment for the comprehensive examination taken by the graduating students for them to have a reliable sets of questions per functions. At the same time, intensify the practical assessment of the students to gauge the knowledge of the students prior to licensure examination.

Other variables related to the present study are recommended to determine additional predictors of success by the graduates in the OIC Navigational Watch Licensure Examination.

\section{References}

[1] Besag F. P. and Besag P. L. 1985. "Statistics for the Helping Professions”, Sage Publications, Inc. Beverly Hills, California.

[2] Alicias Jr. and E. R. 1997. "Data Organization and Analysis in a Computer Environment”, 2nd Edition. Philippine.

[3] Norusis M.J. 2003. "SPSS 12.0 Statistical Procedures Companion”. SPSS Inc. Prentice Hall, Inc.

[4] Gordon E.E. 2005. "Peer Tutoring: A teacher's Resource Guide." Forbes Boulevard (March).

[5] Palgi Y. and Shmotkin D. "Life Satisfaction", Wikipedia, Free Encyclopedia. Access June 13, 2013. http://en.wikipedia.org/wiki/Life_satisfaction. 